\title{
To retain or remove the syndesmotic screw: a review of literature
}

\author{
T. Schepers
}

Received: 28 August 2010/Published online: 16 December 2010

(C) The Author(s) 2010. This article is published with open access at Springerlink.com

\begin{abstract}
Introduction Syndesmotic positioning screws are frequently placed in unstable ankle fractures. Many facets of adequate placement techniques have been the subject of various studies. Whether or not the syndesmosis screw should be removed prior to weight-bearing is still debated. In this study, the recent literature is reviewed concerning the need for removal of the syndesmotic screw.

Materials and methods A comprehensive literature search was conducted in the electronic databases of the Cochrane Library, Pubmed Medline and EMbase from January 2000 to October 2010.

Results A total of seven studies were identified in the literature. Most studies found no difference in outcome between retained or removed screws. Patients with screws that were broken, or showed loosening, had similar or improved outcome compared to patients with removed screws. Removal of the syndesmotic screws, when deemed necessary, is usually not performed before 8-12 weeks.

Conclusion There is paucity in randomized controlled trials on the absolute need for removal of the syndesmotic screw. However, current literature suggests that it might be reserved for intact screws that cause hardware irritation or reduced range of motion after 4-6 months.
\end{abstract}

Keywords Unstable ankle fracture - Syndesmosis . Syndesmotic screw $\cdot$ Transsyndesmotic

T. Schepers $(\square)$

Department of Surgery-Traumatology, Erasmus MC, University Medical Centre, Room H-822k, P.O. Box 2040, CA 3000 Rotterdam, The Netherlands e-mail: t.schepers@erasmusmc.nl

\section{Introduction}

Approximately one in seven ankle fractures is accompanied by a distal tibiofibular syndesmotic disruption [1] When, after stable fixation of the fractured malleoli, persistent instability of the distal tibiofibular joint is identified perioperatively, additional stabilization is indicated. In most cases the syndesmotic ligaments are left untouched and a so-called 'syndesmotic positioning screw' is placed to restore and maintain a congruent mortise.

The theoretical and technical aspects of syndesmotic screw placement have been subject to numerous clinical and biomechanical investigations, in an attempt to solve some of the controversies concerning syndesmotic screw usage. There appears to be no difference in stainless steel versus titanium screws [2]. A $4.5-\mathrm{mm}$ screw apparently provides greater resistance to shear stress than a $3.5-\mathrm{mm}$ screw [3]; however, this does not implicate a biomechanical advantage [4]. The level of placement probably does not affect outcome [5]. Two syndesmotic screws provide more stability than one [6], which seems beneficial in more proximal fibular (Dupuytren and Maisonneuve) fractures and neuropathic fracture dislocation in the diabetic patient [7]. Bioabsorbable screws are biomechanically and clinically equivalent to stainless steel syndesmotic screws [8-12]. Three-cortical versus four-cortical screw placement does not affect biomechanical stability [13, 14], or influence outcome $[4,15-18]$. The use of a suture device seems to provide equal [19] or improved [20] outcome compared to a four-cortical syndesmotic screw. The position of the foot during insertion of the syndesmotic screw does not influence the range of motion or outcome [21-24]. Finally, based on CT scanning, 16-52\% of syndesmoses are not reduced anatomically [25, 26], which will most likely negatively affect outcome [27-32]. 
Whether or not the syndesmotic screw has to be removed prior to weight-bearing is still subject to debate. Proponents of this policy state that tibiofibular movement is affected by leaving the screw in place and dorsiflexion is hampered [33, 34]. This is accompanied by the possibility of breakage of the screw when left in place [35]. Prominent reference books $[36,37]$ in the field of fracture care still advocate removal of the syndesmotic screw prior to weight-bearing at 6-8 weeks, which to date, influence current practice [38, 39]. However, this statement has been disputed since the late 1950s and early 1960s [33, 40-44]. In 1985, De Souza et al. [45] showed that in a group of 30 patients with a syndesmotic screw, of which 12 were left in place, no difference in outcome, pain and motion between retained and removed screws could be detected after an average of 36 months. In addition, leaving the screw in place saves the patient from one extra surgical procedure, including its possible complications.

The current review study challenges the need for routine removal of the syndesmotic screw, despite that removal is currently considered best practice.

\section{Materials and methods}

A literature search was conducted to identify studies in which syndesmotic screws were retained or not routinely removed. The electronic databases between 1 January 2000 and 1 October 2010 of the Cochrane Library, Pubmed Medline and EMbase were explored using the following search terms and Boolean operators: 'syndesmosis' OR 'syndesmotic' OR 'transsyndesmotic' OR 'distal tibiofibular' AND 'screw'. The restriction in publication date was applied to obtain insight into more current practice. Manuscript language was restricted to English, German, and Dutch literature. Publications were requested at the university medical (Internet) library and reviewed. In addition, a comprehensive search of reference lists of all identified articles was conducted to find additional studies. An article was found eligible when it concerned: (1) the surgical treatment for unstable ankle fractures; (2) usage of one or more syndesmotic screws, whether or not compared to an alternative procedure (e.g., suture wire or absorbable screws); and (3) studies included that mentioned the outcome of patients with positioning screws retained and removed. Studies were excluded when they were review, case report or biomechanical studies.

\section{Results}

Figure 1 shows the strategy of the literature search. A total of seven studies mentioning both the outcome of removed

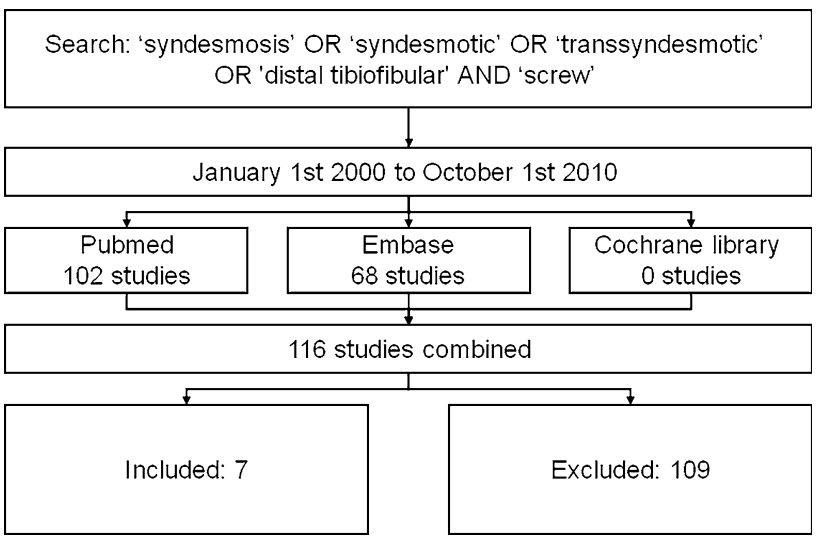

Fig. 1 Flowchart showing literature search

or retained syndesmotic screw were identified in the literature (Table 1). Six studies found no difference in outcome between retained or removed screws [17, 28, 32, 46-48]. In the study by Hamid et al.[47], patients with a broken screw had the highest outcome scores. Manjoo et al. [49] showed a less favorable outcome in retained screws that were intact, but screws that were broken or showed loosening had similar outcome as removed screws. In these seven studies, the time of removal was 3 months on average [17, 28, 32, 46-49]. Manjoo et al. [49] recommended screw removal only when still intact after 6 months.

\section{Discussion}

Recent literature in general does not support routine removal of the syndesmotic screw and outcome appears to be similar both in retained and removed screws [17, 28, 32, 46-48]. However, one study showed lower outcome scores in intact retained screws [49]. In the included studies, broken screws did not result in an adverse effect on outcome, as broken screws had similar or improved outcome over intact screws $[47,49]$. This might be considered a plea for omitting the routine removal of syndesmotic screws. This is reflected in three surveys on syndesmotic screw usage showing increased numbers of retained screws, from $8 \%$ in $2004,14 \%$ in 2008 to $35 \%$ in 2010 [38, 39, 50].

The primary limitation of this review study was that most included studies had a retrospective study design (Table 1). The two studies with the highest level of evidence, comparing three- versus four-cortical screws [17, 48], presented indirect evidence, as these studies were not powered to compare outcome in screws removed or retained. Secondly, it cannot be ruled out that despite a thorough literature search not all related studies were identified. How this would affect the overall conclusion of the current review study is unknown. 
Table 1 Literature overview on after-treatment of syndesmotic screws

\begin{tabular}{|c|c|c|c|c|c|}
\hline Study & LOE & Patients & $\begin{array}{l}\text { Screws } \\
\text { retained }\end{array}$ & $\begin{array}{l}\text { Follow-up } \\
\text { (months) }\end{array}$ & Major findings \\
\hline Hoiness [48] & $1(\mathrm{RCT})$ & 64 & 32 & 12 & $\begin{array}{l}\text { Routine removal of quadricortical screws; no removal } \\
\text { of tricortical screws. Tricortical, at } 3 \text { months } \\
\text { significantly better on OMAS; after } 1 \text { year no } \\
\text { difference in outcome }\end{array}$ \\
\hline Bell [46] & 4 (retrospective cohort) & 30 & 7 (2 broken) & 15 & No significant difference in Baird-Jackson ankle score \\
\hline Weening [32] & 4 (retrospective cohort) & 51 & 21 & 18 & $\begin{array}{l}\text { No significant difference in OMAS and SMFA for } \\
\text { removed and retained screws }\end{array}$ \\
\hline Moore [17] & 2 (quasi-RCT) & 120 & 113 (9 broken) & 5 & $\begin{array}{l}\text { No apparent difference in outcome between retained } \\
\text { and removed screws }\end{array}$ \\
\hline Hamid [47] & 4 (retrospective cohort) & 52 & 25 (10 broken) & 30 & $\begin{array}{l}\text { No significant difference in AOFAS and VAS for intact } \\
\text { and removed screws. Broken screws, best outcome }\end{array}$ \\
\hline Manjoo [49] & 4 (retrospective cohort) & 76 & 64 (44 broken or loose) & 23 & $\begin{array}{l}\text { No significant difference in the lower extremity } \\
\text { measure and OMAS for broken/loose and removed } \\
\text { screws. Intact screws, significantly lower outcome }\end{array}$ \\
\hline Egol [28] & 4 (retrospective cohort) & 79 & 68 (15 broken) & 12 & $\begin{array}{l}\text { No statistical difference in pain, function or range of } \\
\text { ankle motion between removed/broken screws and } \\
\text { retained screws }\end{array}$ \\
\hline
\end{tabular}

LOE level of evidence; FAOS Foot and Ankle Outcome Score; OMAS Olerud-Molander Ankle Score; AOFAS American Orthopedic Foot Ankle Society hindfoot score; SMFA Short Musculoskeletal Function Assessment Questionnaire

On average, the included studies showed removal of the syndesmotic screws after approximately $3-4$ months, usually when intact screws caused hardware irritation or reduced dorsiflexion $[34,49]$. Unprotected weight-bearing in these studies started on average at $6-8$ weeks $[17,28$, 46-49]. Screw removal prior to 8 weeks has been related to loss of reduction at the tibiofibular joint $[51,52]$. One study that did not meet the inclusion criteria showed an increase in outcome and range of motion on standard removal of the syndesmotic screw at approximately 4 months [34]. However, follow-up was short and there was no control group.

A previous review recommended removal of fourcortical screws after $6-8$ weeks, and removal on indication in three-cortical screws [53]. The outcome and stability are similar in tri- and quadricortically placed screws [16-18, 48], and hardware failure is identical in both groups $[17,49]$. Depending on the duration of follow-up, 7-29\% of syndesmotic screws left in place break, with no apparent difference between tricortical and quadricortical screws $[17,19,35,46]$. However, synostosis might occur more frequently in quadricortical screws [16]. In a study by Heim et al., syndesmotic screws were placed tricortically and showed loosening in $91 \%$ of the patients. They therefore stated that early removal of syndesmotic screws was only appropriate when no loosening occurred or limitations in dorsiflexion existed [54]. Hoiness et al. [48] routinely removed quadricortically placed syndesmotic screws, but tricortical screws were removed only in case of hardware complaints. In about $93 \%$ of cases with two tricortical screws, no hardware removal was required in this study
[48]. Thus, metallic syndesmotic screws are probably best placed tricortically, as this prevents secondary surgery to remove hardware in over $90 \%$ of the patients. Removal of hardware might be completely abolished with the use of absorbable screws or suture device [9-12, 19, 20].

In conclusion, the fear of less favorable outcome, if syndesmotic screws are left in situ, is seemingly unfounded. Recent literature shows similar or better results when screws are retained. Screw removal, when intact after 4-6 months, might be justified if the positioning screw gives rise to physical complaints, e.g., when dorsiflexion is hampered or outcome appears to be affected. When one or two syndesmotic screws are placed tricortically, the need for hardware removal is $<10 \%$. The results of these studies need to be verified in randomized controlled trials.

Open Access This article is distributed under the terms of the Creative Commons Attribution Noncommercial License which permits any noncommercial use, distribution, and reproduction in any medium, provided the original author(s) and source are credited.

\section{References}

1. Dattani R, Patnaik S, Kantak A, Srikanth B, Selvan TP (2008) Injuries to the tibiofibular syndesmosis. J Bone Joint Surg Br 90(4):405-410

2. Beumer A, Valstar ER, Garling EH, Niesing R, Heijboer RP, Ranstam J, Swierstra BA (2005) Kinematics before and after reconstruction of the anterior syndesmosis of the ankle: a prospective radiostereometric and clinical study in five patients. Acta Orthop 76(5):713-720 
3. Hansen M, Le L, Wertheimer S, Meyer E, Haut R (2006) Syndesmosis fixation: analysis of shear stress via axial load on 3.5$\mathrm{mm}$ and 4.5 -mm quadricortical syndesmotic screws. J Foot Ankle Surg 45(2):65-69

4. Thompson MC, Gesink DS (2000) Biomechanical comparison of syndesmosis fixation with 3.5- and 4.5-millimeter stainless steel screws. Foot Ankle Int 21(9):736-741

5. Kukreti S, Faraj A, Miles JN (2005) Does position of syndesmotic screw affect functional and radiological outcome in ankle fractures? Injury 36(9):1121-1124

6. Xenos JS, Hopkinson WJ, Mulligan ME, Olson EJ, Popovic NA (1995) The tibiofibular syndesmosis. Evaluation of the ligamentous structures, methods of fixation, and radiographic assessment. J Bone Joint Surg Am 77(6):847-856

7. Thordarson DB (2004) Ankle fractures in diabetics. Techn Foot Ankle Surg 3(3):192-197

8. Cox S, Mukherjee DP, Ogden AL, Mayuex RH, Sadasivan KK, Albright JA, Pietrzak WS (2005) Distal tibiofibular syndesmosis fixation: a cadaveric, simulated fracture stabilization study comparing bio-absorbable and metallic single screw fixation. J Foot Ankle Surg 44(2):144-151

9. Hovis WD, Kaiser BW, Watson JT, Bucholz RW (2002) Treatment of syndesmotic disruptions of the ankle with bioabsorbable screw fixation. J Bone Joint Surg Am 84-A(1):26-31

10. Kaukonen JP, Lamberg T, Korkala O, Pajarinen J (2005) Fixation of syndesmotic ruptures in 38 patients with a malleolar fracture: a randomized study comparing a metallic and a bioabsorbable screw. J Orthop Trauma 19(6):392-395

11. Sinisaari IP, Luthje PM, Mikkonen RH (2002) Ruptured tibiofibular syndesmosis: comparison study of metallic to bioabsorbable fixation. Foot Ankle Int 23(8):744-748

12. Thordarson DB, Samuelson M, Shepherd LE, Merkle PF, Lee J (2001) Bioabsorbable versus stainless steel screw fixation of the syndesmosis in pronation-lateral rotation ankle fractures: a prospective randomized trial. Foot Ankle Int 22(4):335-338

13. Beumer A, Campo MM, Niesing R, Day J, Kleinrensink GJ, Swierstra BA (2005) Screw fixation of the syndesmosis: a cadaver model comparing stainless steel and titanium screws and three and four cortical fixation. Injury 36(1):60-64

14. Nousiainen MT, McConnell AJ, Zdero R, McKee MD, Bhandari M, Schemitsch EH (2008) The influence of the number of cortices of screw purchase and ankle position in Weber $\mathrm{C}$ ankle fracture fixation. J Orthop Trauma 22(7):473-478

15. Hoiness P, Engebretsen L, Stromsoe K (2003) Soft tissue problems in ankle fractures treated surgically. A prospective study of 154 consecutive closed ankle fractures. Injury 34(12):928-931

16. Karapinar H, Kalenderer O, Karapinar L, Altay T, Manisali M, Gunal I (2007) Effects of three- or four-cortex syndesmotic fixation in ankle fractures. J Am Podiatr Med Assoc 97(6):457-459

17. Moore JA Jr, Shank JR, Morgan SJ, Smith WR (2006) Syndesmosis fixation: a comparison of three and four cortices of screw fixation without hardware removal. Foot Ankle Int 27(8):567-572

18. Wikeroy AK, Hoiness PR, Andreassen GS, Hellund JC, Madsen JE (2010) No difference in functional and radiographic results 8.4 years after quadricortical compared with tricortical syndesmosis fixation in ankle fractures. J Orthop Trauma 24(1):17-23

19. Cottom JM, Hyer CF, Philbin TM, Berlet GC (2009) Transosseous fixation of the distal tibiofibular syndesmosis: comparison of an interosseous suture and endobutton to traditional screw fixation in 50 cases. J Foot Ankle Surg 48(6):620-630

20. Thornes B, Shannon F, Guiney AM, Hession P, Masterson E (2005) Suture-button syndesmosis fixation: accelerated rehabilitation and improved outcomes. Clin Orthop Relat Res 431:207-212

21. Bragonzoni L, Russo A, Girolami M, Albisinni U, Visani A, Mazzotti N, Marcacci M (2006) The distal tibiofibular syndesmosis during passive foot flexion. RSA-based study on intact, ligament injured and screw fixed cadaver specimens. Arch Orthop Trauma Surg 126(5):304-308

22. Olerud C (1985) The effect of the syndesmotic screw on the extension capacity of the ankle joint. Arch Orthop Trauma Surg 104(5):299-302

23. Rao SE, Muzammil S, Khan AH (2009) Technique of syndesmotic screw insertion in weber $\mathrm{C}$ ankle fractures. J Surg Pak 14(2):58-62

24. Tornetta P 3rd, Spoo JE, Reynolds FA, Lee C (2001) Overtightening of the ankle syndesmosis: is it really possible? J Bone Joint Surg Am 83-A(4):489-492

25. Gardner MJ, Demetrakopoulos D, Briggs SM, Helfet DL, Lorich DG (2006) Malreduction of the tibiofibular syndesmosis in ankle fractures. Foot Ankle Int 27(10):788-792

26. Schwarz N, Köfer E (2005) Postoperative computed tomographybased control of syndesmotic screws. Eur J Trauma 31(3):266-270

27. Chissell HR, Jones J (1995) The influence of a diastasis screw on the outcome of Weber type-C ankle fractures. J Bone Joint Surg Br 77(3):435-438

28. Egol KA, Pahk B, Walsh M, Tejwani NC, Davidovitch RI, Koval KJ (2010) Outcome after unstable ankle fracture: effect of syndesmotic stabilization. J Orthop Trauma 24(1):7-11

29. Kennedy JG, Soffe KE, Dalla Vedova P, Stephens MM, O'Brien T, Walsh MG, McManus F (2000) Evaluation of the syndesmotic screw in low Weber $\mathrm{C}$ ankle fractures. J Orthop Trauma 14(5):359-366

30. Leeds HC, Ehrlich MG (1984) Instability of the distal tibiofibular syndesmosis after bimalleolar and trimalleolar ankle fractures. J Bone Joint Surg Am 66(4):490-503

31. Mont MA, Sedlin ED, Weiner LS, Miller AR (1992) Postoperative radiographs as predictors of clinical outcome in unstable ankle fractures. J Orthop Trauma 6(3):352-357

32. Weening B, Bhandari M (2005) Predictors of functional outcome following transsyndesmotic screw fixation of ankle fractures. J Orthop Trauma 19(2):102-108

33. Hooper J (1983) Movement of the ankle joint after driving a screw across the inferior tibiofibular joint. Injury 14(6):493-506

34. Miller AN, Paul O, Boraiah S, Parker RJ, Helfet DL, Lorich DG (2010) Functional outcomes after syndesmotic screw fixation and removal. J Orthop Trauma 24(1):12-16

35. Melvin JS, Downing KL, Ogilvie CM (2008) A technique for removal of broken cannulated tricortical syndesmotic screws. J Orthop Trauma 22(9):648-651

36. Hahn DM, Colton CL (2001) Malleolar fractures. In: Rüedi TP, Murphy WM (eds) AO principles of fracture management. Thieme, New York, pp 583-584

37. Tile M (2005) Fractures of the ankle. In: Schatzker J, Tile M (eds) The rationale of operative fracture care. Springer-Verlag, New York, pp 580-581

38. Monga P, Kumar A, Simons A, Panikker V (2008) Management of distal tibiofibular syndesmotic injuries: a snapshot of current practice. Acta Orthop Belg 74(3):365-369

39. Wood GCA, Feldman YA (2004) Indications and use of the ankle syndesmosis screw: a multi-regional survey. Foot Ankle Surg 10:65-69

40. Costigan PG (1953) Treatment of true widening ankle mortise. Can Med Assoc J 69(3):310-313

41. Grath GB (1960) Widening of the ankle mortise. A clinical and experimental study. Acta Chir Scand 263(Suppl):1-88

42. Mullins JF, Sallis JG (1958) Recurrent sprain of the ankle joint with diastasis. J Bone Joint Surg Br 40-B(2):270-273

43. Smith MG (1963) Inferior tibiofibular diastasis treated by cross screwing. J Bone Joint Surg Br 45:737-739

44. Vasli S (1957) Operative treatment of ankle fractures. Acta Chir Scand 226(Suppl):1-74 
45. de Souza LJ, Gustilo RB, Meyer TJ (1985) Results of operative treatment of displaced external rotation-abduction fractures of the ankle. J Bone Joint Surg Am 67(7):1066-1074

46. Bell DP, Wong MK (2006) Syndesmotic screw fixation in Weber $\mathrm{C}$ ankle injuries: should the screw be removed before weight bearing? Injury 37(9):891-898

47. Hamid N, Loeffler BJ, Braddy W, Kellam JF, Cohen BE, Bosse MJ (2009) Outcome after fixation of ankle fractures with an injury to the syndesmosis: the effect of the syndesmosis screw. J Bone Joint Surg Br 91(8):1069-1073

48. Hoiness P, Stromsoe K (2004) Tricortical versus quadricortical syndesmosis fixation in ankle fractures: a prospective, randomized study comparing two methods of syndesmosis fixation. J Orthop Trauma 18(6):331-337

49. Manjoo A, Sanders DW, Tieszer C, MacLeod MD (2010) Functional and radiographic results of patients with syndesmotic screw fixation: implications for screw removal. J Orthop Trauma 24(1):2-6

50. Bava E, Charlton T, Thordarson D (2010) Ankle fracture syndesmosis fixation and management: the current practice of orthopedic surgeons. Am J Orthop (Belle Mead NJ) 39(5):242-246

51. Donatto KC (2001) Ankle fractures and syndesmosis injuries. Orthop Clin North Am 32(1):79-90

52. Roberts RS (1983) Surgical treatment of displaced ankle fractures. Clin Orthop Relat Res 172:164-170

53. van den Bekerom MP, Hogervorst M, Bolhuis HW, van Dijk CN (2008) Operative aspects of the syndesmotic screw: review of current concepts. Injury 39(4):491-498

54. Heim D, Schmidlin V, Ziviello O (2002) Do type B malleolar fractures need a positioning screw? Injury 33(8):729-734 